\title{
Energy Efficient Landscape for Thermal Comfort in Buildings and Built-up Areas
}

\author{
Srikonda Ramesh
}

\begin{abstract}
Energy and landscape are critical constituents in the physical development of built environment. Energy conservation and landscape quality have been widely acknowledged as important parameters in design of building, surroundings and built-up Areas. In design process the landscape is one of the vital parameters of functional, aesthetical and environmental considerations. It is essential to understand its contribution towards energy and environment to enable the designer to utilize its potential effectively in an integrated design approach and thought process with due consideration to climate change. It has a potentiality to dilute the greenhouse effect, absorb the dust particulates, sound and to bring strong impact on micro climate and sol-air temperature. This paper deals precisely, how the energy efficient landscape parameters can be assessed to integrate in the built up spaces so as to conserve the energy. The investigation has been carried to understand the energy conservation potential of ground for space conditioning for earth coupled buildings, soft and hard surfaces. The sol-air temperature of different surfaces and its influence on the micro climate around built spaces; thermal behavior of different vernacular/traditional materials have been analyzed with reference to diffusivity, decrimental factor, time lag and found that red sand stone pavers had shown better variation as compared to concrete, lime concrete and brick pavers. It is also emphasized the impotence of shading considerations and vegetation to reduce the heat island effect.
\end{abstract}

Index Terms-Sol-air temperature, earth coupled structures, earth temperatures for different soils, plant materials, dust, and sound.

\section{INTRODUCTION}

The landscape design not only enhances the environment but also works as an effective tool to conserve the conventional energy in several ways as referred in [1], [2]. The terrace gardens, land profiles, earth berm structures, earth air tunnels, roof ponds, hard surfaces, vegetation and shading of deciduous / evergreen trees with respect to sun path and seasonal variations can directly contribute to bring eco-friendly built up areas and high green rating buildings which is the need of the day so as to conserve the energy in a natural means as described in [3], [4]. So it is essential and crucial to understand the energy efficient parameters in order to achieve an energy efficient built environment. The primary landscaping features which influence the micro climate of the built environment are Earth and landform, Vegetation, Water body, hard landscape and Soft landscape can be designed to

Manuscript received January 19, 2015; revised May 1, 2015.

Srikonda Ramesh is with School of Planning and Architecture: Vijayawada, India. Former Chief Architect, MCD, Delhi, India (e-mail: ramesh.srikonda@spav.ac.in) have thermal energy savings as in [5], [6]. It is essential to understand the thermal behavior of the earth to utilize it effectively in the deign process. Similarly the potentialities of vegetation and water body have to be analyzed with collective integration and with conscious direction to obtain the desirable results to conserve the precious convention energy.

\section{EARTH AND LANDFORM}

As Thermal comfort conditions become a concern several research organizations have been focused on their study of heat Transfer in the built environment. The building fabric itself can be utilized to control the inside environment as emphasized in [7], [8]. Earth offers many benefits suitable for application to space conditioning due to its thermal behavior. The application of earth for space conditioning has often viewed itself in the direct coupled context as in basement and Earth shelters.

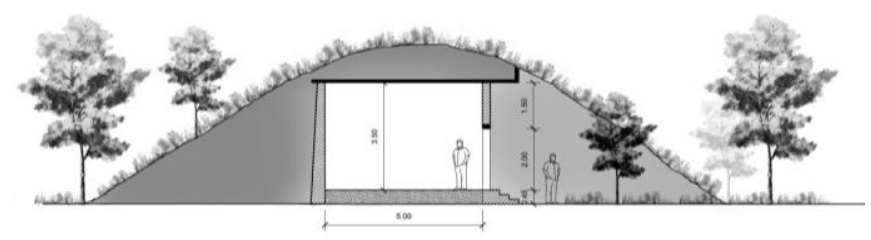

(a). Direct earth coupled.

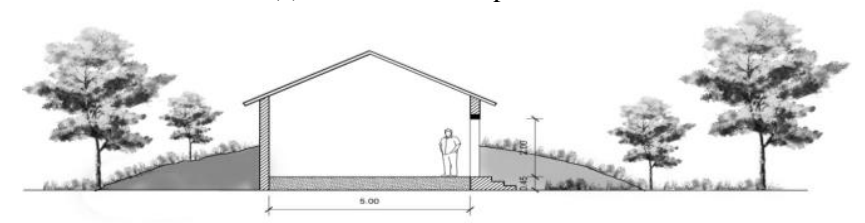

(b). Indirect earth coupled.

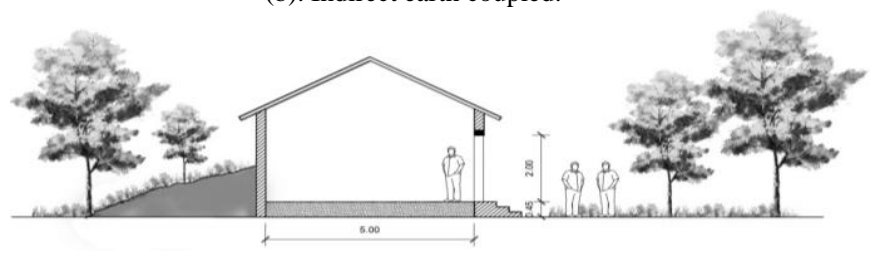

(c). Semi passive earth coupled

Fig. 1. Earth coupled buildings.

\section{A. Earth Coupled Buildings}

The earth coupled buildings can be designed as direct coupled and indirect coupled Buildings. The buildings or spaces that are directly in contact with earth i.e., covered /surrounded completely or partially with earth as external medium are called direct earth coupled spaces. All basements, cellars, Earth - berm structures, can be termed in this category. Buildings which use the heat transfer quality of Earth indirectly or partially through a heat transfer medium for heating \& cooling can be categorized as indirect Earth 
Coupled Buildings. Spaces that are coupled with various passive devices like earth air tunnel, rock bed storage or other such heat storage in ground coupled to the space conditioning fall in semi passive category as in [9]-[11]. The conceptual designs of such buildings have been given in Fig. 1.

The thermal properties of the earth are the major factor to bring micro climatic differences in the built environment. The earth temperature is one of the major parameters to integrate or to set the building in a site with respect to landscape elements. The use of earth to air heat exchangers has gained an increasing importance and acceptance with due understanding of integration of thermal behavior of earth during the recent years as in [12], [13]. However, there is an inadequate emphasis on the performance of the exchangers with the building as in [14]. It is pre requirement to understand the thermal properties of the various soils to determine the earth temperature. The undisturbed earth temperature can be found by the equation (1).

$$
T(z, t)=T_{g}-A_{s o} e^{-2[\sqrt{\pi / \tau \alpha}]} \operatorname{Cos}\left[\frac{2 \pi}{\tau}\left(t-t_{o}-\frac{z}{2} \sqrt{\frac{\tau}{\pi \alpha}}\right)\right]
$$

where

$T(z, t)$ Ground Temperature at any depth ' $Z$ ' and time $t$ $\left({ }^{0} \mathrm{C}\right)$

$T_{g}$ Annual mean ground temperature, considered equal to annual mean air Temperature $\left({ }^{\circ} \mathrm{C}\right)$

$A_{\text {so }}$ Annual surface temperature amplitude

$t \quad$ Day of the year $(1$ year $=365$ days $)$

$t_{o} \quad$ Phase constant (days)

$z \quad$ Depth from the surface $(\mathrm{m})$

$\alpha \quad$ Soil thermal diffusivity

$\tau$ Time period of the annual Temperature of the wave (365 days)

The thermal properties of soil influence the earth temperature. These properties can be incorporated to calculate the Earth temperature in different depths. The thermal properties of different soils have been listed below (Table I).

TABLE I: THERMAL PROPERTIES OF DIFFERENT SOILS

\begin{tabular}{|l|l|l|l|l|l|}
\hline $\begin{array}{r}\text { Sl } \\
\text { no }\end{array}$ & \multicolumn{1}{|c|}{ Soil type } & $\begin{array}{c}\mathrm{K} \\
(\mathrm{KJ} / \mathrm{hmk})\end{array}$ & $\begin{array}{c}\rho \\
\left(\mathrm{Kg} / \mathrm{m}^{3}\right)\end{array}$ & $\begin{array}{c}\mathrm{C} \\
(\mathrm{KJ} / \mathrm{KgK})\end{array}$ & $\begin{array}{c}\mathrm{D} \\
\left(\mathrm{m}^{2} / \mathrm{sec}\right)\end{array}$ \\
\hline 1. & Organic soil & 0.9 & 1300 & 1.92 & 0.01 \\
\hline 2. & Sand & 10.44 & 2650 & 0.73 & 0.13 \\
\hline 3. & $\begin{array}{l}\text { Light soil } \\
(\text { dry })\end{array}$ & 1.26 & 1440 & 0.85 & 0.03 \\
\hline 4. & $\begin{array}{l}\text { Lightsoil } \\
\text { (wet) }\end{array}$ & 3.132 & 1600 & 1.05 & 0.05 \\
\hline
\end{tabular}

The average Day Temperature $31{ }^{\circ} \mathrm{C}$ and thermal properties of the light soil (dry) have been used as an input to understand the earth temperature profiles incorporating in the above said equation $T(z, t)$. The result has been plotted in Fig. 2. It can be seen that the annual temperature variations reduces with depth and attains the annual mean air temperature as the soil temperature, after certain depth. It is the lowest for organic and maximum for sand soil that depends on the thermal diffusivity of the soil. It can be noticed that organic soil attains instant annual temperature at a depth of even less than $8 \mathrm{~m}$ while sand stabilizes at a depth of over $10 \mathrm{~m}$. These results can be of great use to work out appropriate thermal comfort conditions to the direct and indirect earth coupled buildings. As the earth temperature is constant beyond the $8-10 \mathrm{~m}$ depth, the earth air temperature also has more or less the same temperature throughout the year and it can be effectively integrated in buildings for heating and cooling requirements in composite climatic zones by earth air tunnels. The earth temperature is beyond $6 \mathrm{~m}$ is $27.5^{\circ} \mathrm{C}$ and nearer to $23.5^{\circ} \mathrm{C}$ for cooling and heating seasons respectively, so that the temperature of the undisturbed earth can be a potential input for integrating the same to a building envelope for thermal comforts as in [15] and [16]. The shaded and un-shaded surfaces and related earth temperature can be utilized to integrate with built forms for desirable environmental conditions. Different soil conditions that are elaborated above can be a vital factor for determining the undisturbed temperature for integrating the built forms to establish eco-friendly environment.

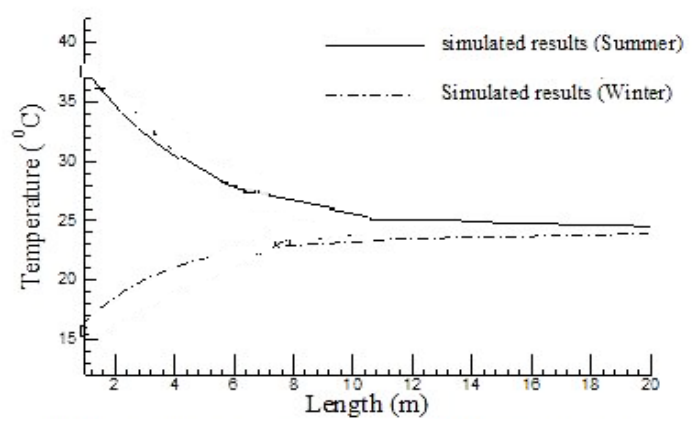

Fig. 2. Earth temperature vs. depth.

\section{VEGETATION IN LANDSCAPE}

The attitude of limiting landscape design only to the sphere of decoration and aesthetics should also be shifted towards the comfort point of view as well. Trees \& green areas around a building or town improve the physical comfort along with the visual pleasure. It has been concluded in the literature [17] that even thick $50-100 \mathrm{~m}$ of broad vegetation around city of Frankfurt can reduce the air temperature up to $3.5^{\circ} \mathrm{C}$. The soft landscape can contribute to healthy environment in the following areas:

- Air-cooling

- Increase in the relative humidity

- Fresh air supply

- Air filtration

- Noise absorption

- Oxygen production

Thermal conditions of the environment with respect to cooling \& air filtering depend upon the quantity of foliage. The literature indicates that around $80 \%$ of the incident solar radiation is controlled within the foliage and only 5\% penetrates and reaches the ground as in [18]. Vegetation helps in lowering down the air temperature of surroundings 
by evaporative cooling as a result of its transpiration. Tree leaves/foliage obstruct the passage of sunrays and through the process of photosynthesis by consuming radiant energy, thereby providing the desired cooling effect to the surrounding thermal environment as in [19]. To achieve maximum efficiency the trees have to be placed/located scientifically because shape, size and foliage of trees have direct impact/effect on their shadows and the sun rays penetration. The energy efficient landscape design should permit winter penetration at the same time giving provision for blocking summer heat penetration. The Table II gives the percentage penetration of light through evergreen \& deciduous type of trees for composite climatic zone where there is some amount of cooling is required in summer and similarly the other way of heating on winter. This is a contributory knowledge to design the windows for day lighting. The sizing of the windows is basically to admit the diffused daylight and to contribute desirable ventilation in order to have adequate number of air changes in buildings. It is evident that the trees can play an impressive parameter to design the windows for diffused day lighting and ventilation with respect to the shading of the windows and allowing the air to pass with regard to wind direction respectively as indicated in [20], [21].

TABLE II: Light PENETRATION THROUGH TREES

\begin{tabular}{|l|l|l|l|}
\hline \multirow{2}{*}{ Type of forest } & Percentage of light penetration \\
\cline { 2 - 4 } & April & May & September \\
\hline Evergreen & 8 & 7 & 4 \\
\hline Deciduous & 51 & 23 & 5 \\
\hline
\end{tabular}

(Source: Architect's Guide to Energy Conservation, Jarmul, Seymour)

To avoid the western and eastern solar radiation in summer in 'hot and humid' and 'hot and dry' climatic zones, long oval shaped trees as shown in Fig. 2 having the spread half of the height and foliage in oval shape and having height $25^{\prime} 0$ '"-35'0" are useful because the lower sun rays cast long shadow on the pedestrians path and wall surface. The shaded walls areas generally admit only diffuse solar radiation and in turn the sol-air temperature on exposed wall surface with respect to the external heat transfer coefficient of the material can decrease the indoor air temperature by $3{ }^{\circ} \mathrm{C}$ to $4{ }^{\circ} \mathrm{C}$.

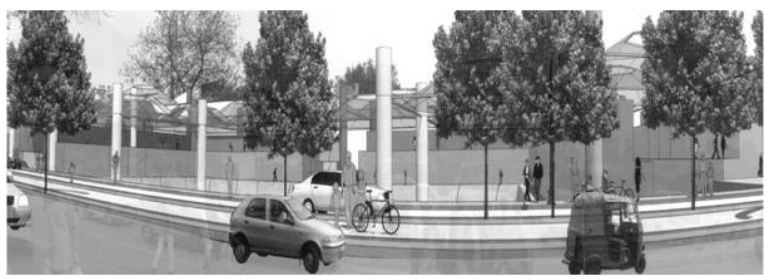

Fig. 2. Western solar radiation through oval shape trees.

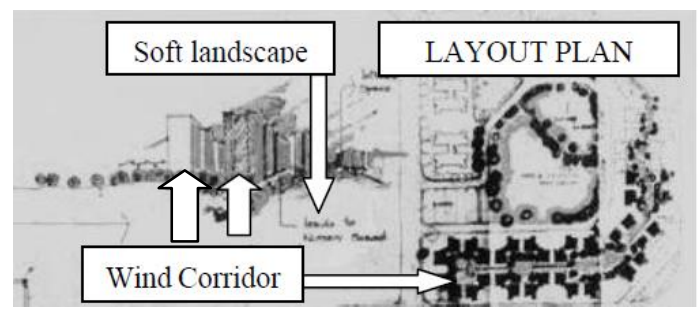

Fig. 3. Wind corridor through trees in a built up areas.

Trees with less spread and height of 20'-30' are useful in directing breezes into particular direction (Fig. 3). Summer breeze provides significant cooling effect if directed properly over the soft areas. The solair temperature of the dry soft areas is $3{ }^{\circ} \mathrm{C}$. lesser and a wet soft area is $5^{\circ} \mathrm{C}$ lesser when compared to the hard/paved surface. The potential of the soft scape can be integrated in the design to bring the comfort conditions in built up spaces by natural means to conserve the energy.

Sphere shaped trees like mango, neem, banyan etc. having the spread and height almost same with the height 30'-50' are useful for the roof shading and these can be located on south east, south and south west sides in northern latitudes (Fig. 4). Shrubs shall be planted in the area where constant shading is desirable [22]. Shrubs planted like hedge obstruct the natural air direction. It is very much essential to plant them considering the predominant wind direction and climate condition of the place so as to utilize its potentiality to the maximum extent.

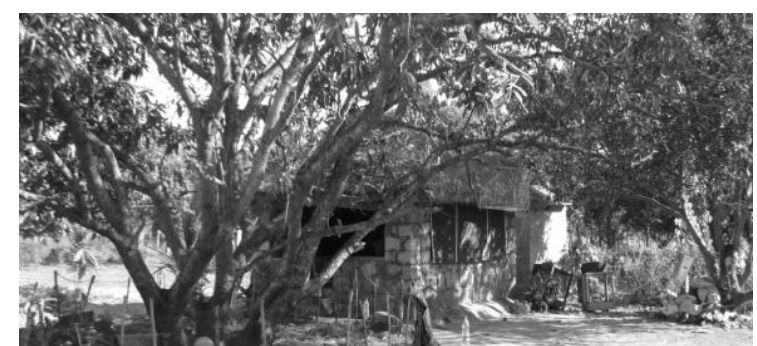

Fig. 4. Round shaped tree for roof shading (ravicherla, krishna district, AP).

Shading by vegetation is an effective method of cooling the prevalent hot air and protecting the building from the solar radiation. The absorbed solar radiation by the leaves of the plant or tree is mainly utilized for photosynthesis and for evaporative heat loses. Energy balance on a leaf specified in the literature is in the order of $20-40 \%$ evaporation, $5-20 \%$ reflection, $10-15 \%$ heat, 5-30\% light transmission and 5-20\% photosynthesis. A study of parker shows that the ambient air under the tree adjacent to the wall is about $2-2.5{ }^{\circ} \mathrm{C}$ cooler than the un-shaded area. Several scientists emphasized the importance of landscape to bring changes in microclimate. Reference [23] categorized certain trees and their salt tolerance along with the suitability for different climatic zones, as many trees will not survive saline conditions (Table III).Roof-shading concept is mainly for the purpose of reducing the transmittance of heat from the roof medium as the roof contributes $50 \%$ of the heat to a building (see Fig. 5).

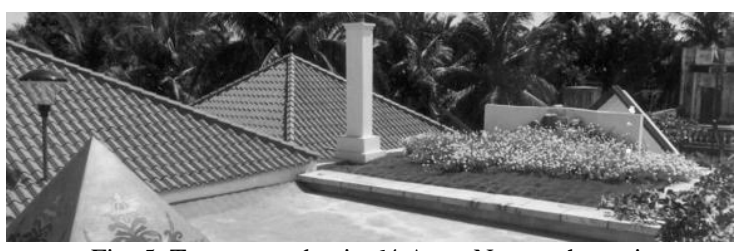

Fig. 5. Terrace garden in 64 Anna Nagar, chennai.
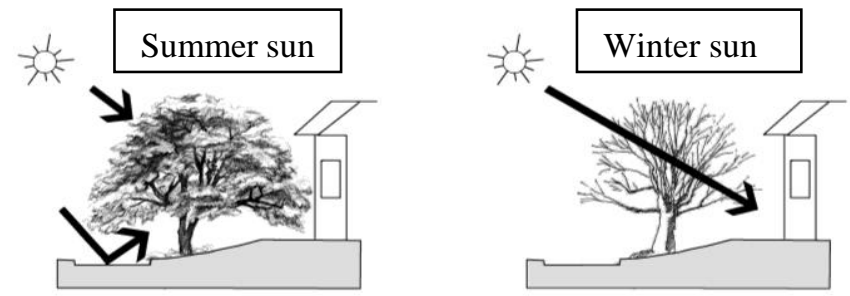

Fig. 6. Deciduous trees covering the southern side façade. 
Trees next to the building can be designed/located with respect to the sun path to shade the roof. The deciduous trees are quite suitable for composite climate for allowing solar radiation to heat the building during winter and avoid direct beam radiation during summers as shown Fig. 6 .

Terrace gardens not only contribute in reducing the heat transmittance through roof but also provide micro climatic thermal conditions.

TABLE III: CATEGORIZATION OF TREES SUITABLE FOR DIFFERENT Climatic ZONES

\begin{tabular}{|c|c|c|c|}
\hline $\begin{array}{l}\text { Sl. } \\
\text { no }\end{array}$ & Common name & Height $[\mathrm{m}]$ & Climate zone \\
\hline \multicolumn{4}{|c|}{ Deciduous trees } \\
\hline 1 & Florida Elm & 15 & $\mathrm{CC}$ \\
\hline 2 & GumboLimbo & 15 & $\mathrm{HD}, \mathrm{MO}$ \\
\hline 3 & Mulberry & $18-24$ & $\mathrm{HD}, \mathrm{MO}$ \\
\hline 4 & Laurel Oak & $18-24$ & $\mathrm{CC}$ \\
\hline 5 & Red Mulberry & 15 & $\mathrm{CO}, \mathrm{MO}$ \\
\hline 6 & Sweet Gum & 24 & WH \\
\hline 7 & Sycamore & 30 & WH \\
\hline \multicolumn{4}{|c|}{ Evergreen trees } \\
\hline 1 & American Holly & 12 & $\mathrm{CC}, \mathrm{CS}$ \\
\hline 2 & Cherry Laurel & 9 & $\mathrm{CO}, \mathrm{MO}$ \\
\hline 3 & Dahoon Holly & 12 & $\mathrm{CC}, \mathrm{MO}$ \\
\hline 4 & Loblolly bay & 15 & $\mathrm{CC}, \mathrm{MO}$ \\
\hline 5 & Pitch apple & 9 & WH \\
\hline 6 & Red mangrove & 22 & $\mathrm{WH}, \mathrm{CO}$ \\
\hline 7 & Magnolia & 24 & $\mathrm{CC}, \mathrm{MO}$ \\
\hline 8 & Red cedar & 9 & $\mathrm{WH}, \mathrm{CC}$ \\
\hline 9 & spruce pine & 30 & $\mathrm{CC}, \mathrm{MO}$ \\
\hline \multicolumn{4}{|c|}{ Evergreen shrubs } \\
\hline 1 & Cocoplum & 6 & WH,CO \\
\hline 2 & Galiberry & 3 & $\mathrm{CC}, \mathrm{CS}, \mathrm{WH}$ \\
\hline 3 & Inkberry & 2 & $\mathrm{WH}, \mathrm{HD}, \mathrm{CO}$ \\
\hline 4 & Marlberry & 6 & $\mathrm{WH}, \mathrm{MD}, \mathrm{CC}$ \\
\hline 5 & Sea Lavender & 2 & WH \\
\hline 6 & Spanish Bayonet & 6 & $\mathrm{CC}, \mathrm{CO}, \mathrm{WH}$ \\
\hline 7 & Wild Coffee & 4 & WH,HD \\
\hline
\end{tabular}

Note: CC: Cold and Cloudy; CO: Composite; CS: Cold and Sunny; HD: Hot and Dry; WH: Warm and Humid; MO : Moderate

The energy balance of leaf can indicate the absorption, reflection and evaporation etc to enable the designer to utilize for designing the desired environment.

- Trees such as Teak, Shisham, palash, Neem, Amaltas, Kachnar, Subabul, Mohua, Imli, Jamun, Harda, etc are the best for general pollution abatement.

- Gular [Ficusglomerata], Asan [Terminaliantomentosa], Banyan [Ficusbenghalensis] can be utilised for air pollution attenuation.

- Neem [Azadiarchtaindica], Mahaneem [Meliaazaderach], Arjun [Ternimaliaarjuna] and Amaltas [Cassia fistula] are generally used as dust absorbers.

- Teak [Tectonagrandis], Palash [Buteamonosperma], Aam [mangiferaindica] and Shisham [Dalbergiasissoo] are proved to be the best for noise breaker and even for green belt development.

It has been noted that the shading reduces surface temperatures below the tree canopy. These cooler surfaces may reduce the heat transmitted into buildings and the immediate micro environment. For The surface temperature reductions are ranging from $11-25^{\circ} \mathrm{C}$ for walls and roofs at two buildings. A detailed study had been conducted to examine the effects of vines on wall temperatures and found reductions up to $20^{\circ} \mathrm{C}$ as in [24] . Further, it was emphasized and found that tree shading reduces the temperatures inside parked cars by about $25^{\circ} \mathrm{C}$ as mentioned in [25]. Similarly, it was indicated by [26] that Evapotranspiration, alone or in combination with shading, can help reduce peak summer air temperatures. Various studies in the literature have measured the following reductions:

- Peak air temperatures in tree groves that are $9{ }^{\circ} \mathrm{F}\left(5^{\circ} \mathrm{C}\right)$ cooler than over open terrain.

- Air temperatures over irrigated agricultural fields that are $6{ }^{\circ} \mathrm{F}\left(3{ }^{\circ} \mathrm{C}\right)$ cooler than air over bare ground.

- Suburban areas with mature trees that are 4 to $6^{\circ} \mathrm{F}$ (2 to $3{ }^{\circ} \mathrm{C}$ ) cooler than new suburbs without trees.

- Temperatures over grass sports fields that are 2 to $4{ }^{\circ} \mathrm{F}$ (1 to $2^{\circ} \mathrm{C}$ ) cooler than over bordering areas.

\section{Pollutant Removal through DRy DePOSITION}

Plants generally take up gaseous pollutants, primarily through leaf stomata, that then react with water inside the plant to form acids and other chemicals. Plants can also intercept particulate matter as wind currents blow particulates into contact with the plants' surfaces. Some particulates are absorbed into the plant while others adhere to the surface, where they can be re-suspended into the atmosphere by winds or washed off by rain to the soil beneath. These processes can reduce various pollutants found in the urban environment, including particulate matter (PM), nitrogen oxides $\left(\mathrm{NO}_{\mathrm{X}}\right)$, sulfur dioxide $\left(\mathrm{SO}_{2}\right)$, carbon monoxide $(\mathrm{CO})$, and ground-level ozone as indicated by [26].Water is an architectural element that has been used extensively in our ancient buildings and gardens not only because of the aesthetic factors but by realising its efficiency in regulating the micro climate. These properties of water can be utilised in modern buildings for energy conservation (Fig. 7). Water has the potential to improve the physical comfort by evaporative process. Evaporation of water absorbs a significant amount of heat. A fine spray of water fountain further reduces the air temperature due to maximum surface contact between air and water. The rate of heat loss depends upon the relative velocity of water and air during contact, the difference between wet bulb temperature of air and initial temperature of water and the time of contact between air and water. Water bodies were used as an integral part of building complex in built up spaces of several archeologically important cities. The large water feature planned all along the facade on the side of prevailing wind direction can contribute directly to bring immediate micro climatic change in the environment.

- The water body and its properties of evaporation can be utilized to bring immediate change in micro climatic conditions of that area.

- Integrating the water body with the built environment contributes in lowering the ambient temperature in hot $\&$ dry regions, thus providing respite from scorching 
heat.The water body, wind direction and land form are the vital design parameters and front liner to integrate built form in the given topography for thermal and micro climatic conditions.

- The water body has greater thermal heat storage capacity when compared to any other phase changing material; the same has been explored as heat exchanger in cold regions for thermal comfort conditions for conserving the energy.

\section{GROUND SuRFACE AND PAVING}

The property of ground surfaces around the building, influences the air temperature of surroundings. Hard and polished surfaces like, bare earth, asphalt, sand and concrete become excessively hot due to the solar radiation during the day and increase the air temperature in-and-around the structure and produce discomfort due to glare and re-radiation. The Table IV gives the reflected light percentage of different materials. The reflective coefficient can be a guiding tool for specifications of the surfacing/toping materials in hard landscape.

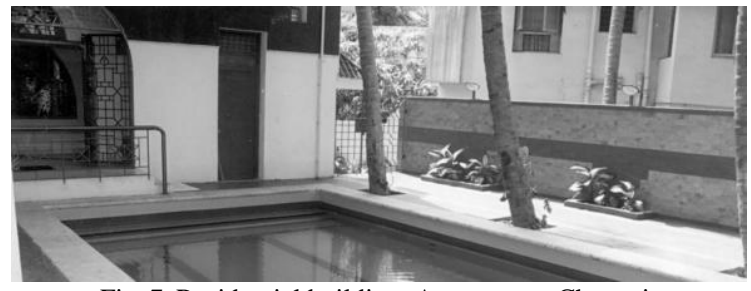

Fig. 7. Residential building, Anna nagar, Chennai.

TABLE IV: INCIDENT LIGHT REFLECTED FROM GROUND

\begin{tabular}{|l|l|l|}
\hline \multicolumn{2}{|l|}{ Material } & Percentage reflected \\
\hline \multirow{2}{*}{ White paint } & New & 75 \\
\cline { 2 - 3 } & Old & 55 \\
\hline & New & 74 \\
\cline { 2 - 3 } & Old & 64 \\
\hline Concrete & 55 \\
\hline Marble (white) & 45 \\
\hline Granite & 40 \\
\hline Brick; Buff dark glazed & 48 \\
\hline Dark glazed & 30 \\
\hline Vegetation & 25 \\
\hline Macadam & 18 \\
\hline
\end{tabular}

(Source: Architect's Guide to Energy Conservation, Jarmul, Seymour.)

The ground covering such as grass is an important surface element as it reduces the incidence of heat and the glare. Grass preserves moisture in root system and reduces heat transfer. Very little heat is stored in vegetation due to its minimal mass but it covers the dry surface of the earth. The lower day temperature and lower night temperature of planted surfaces result in less window heat gain $\&$ a reduced air conditioning burden compared to a situation having paved surface adjacent to the building.

$$
T_{S A}{ }^{j}(t)=\left\{T_{A}(t)+\alpha S^{j}(t) / h_{1}^{j}-\varepsilon \Delta R / h_{1}^{j}\right\}
$$

The sol-air temperature of the surfaces is the major contributors of the heat island effect, it is the heated air film created over the surface of the paved and non paved areas, created due to the combined effect of solar radiation $\left(T_{S A}\right)$ and ambient air temperature $\left(T_{A}\right)$. The thermal properties of the surfaces such as heat transfer quotient of the material $\left(h_{i}\right)$, emissivity $(\varepsilon)$ of surface, absorption $(\alpha)$ of radiant heat and resistance $(R)$ generates to the Solair temperature and it may be calculated by. Besides, each paved surface has different $T_{S A}$, with respect to the thermal properties of the paved areas and earth temperature, especially the shaded and soft surfaces can reduce the heat island effect. The solair temperature of surface shown $7{ }^{\circ} \mathrm{C}$ to $10{ }^{\circ} \mathrm{C}$ variation with direct beam radiation to diffused radiation (shaded surface and un-shaded surface), besides study can be further extended to workout different materials with respect to thermal properties of the materials to select the appropriate specifications to the exposed surfaces around the buildings and external features of the neighborhood, even to macro level.

- The knowledge about surface sol-air temperature of different materials is essential to work out air carrying convection temperature towards a building for which the designer has an interest to optimise thermal environment in and around built up areas.

- The wind direction, speed and the surface materials are contributors for variations in sol-air temperature swings.

- The grass covering to surface can reduce the heat reflection due to its high absorbing capacity so as to provide less sol-air temperature around the built up areas, which is a desirable environment for hot \& dry regions.

\section{THERMAL BEHAVIOR}

One of the important thermal properties of the hard landscape material is thermal conductivity. The inverse of the thermal conductivity is resistivity which, as the name implies, is a measure of the resistance that the material offers to the passage of the heat through it. Another important property of the material is the volumetric heat capacity that is equal to the quantity of heat required to raise the temperature per unit volume of the material by $1{ }^{\circ} \mathrm{C}$. This is given by the product of specific heat and density of the material. Thermal diffusivity is the ratio of the heat conducted by the material to the heat stored in it and is given in $\mathrm{m}^{2}$ /hour. It determines the rate at which a non-uniform temperature distribution approaches equilibrium condition. The thermal conductivity is a physical property of a medium and defines the ability of a substance to conduct heat. For treatment of hard surfaces, it is generally considered to be constant. Thermo-physical properties of common construction materials used for hard land landscape are shown in Table $\mathrm{V}$.

The phase lag is the time delay between the impact of the diurnal variation of the temperature and radiation on the external surface, and the resultant temperature variation on the internal surface. The heat stored capacity of the building components, plays an important role in determining the phase lag bringing marked difference between the time dependent thermal performance of heavy weight and low weight structures under such circumstances [27]. The time lag for homogeneous materials subject to the temperature 
fluctuations with a 24 hours period is given approximately by the formula:

$$
\psi^{\prime}=1.38 L \sqrt{\frac{1}{\bar{v}}}
$$

where $\psi^{\prime}$ is the time $\operatorname{lag}($ in seconds) $L$ is the thickness(m) and $(\bar{v}=k / \rho)$ is the thermal diffusivity $\left(\mathrm{m}^{2} / \mathrm{s}\right)$. The thermal behaviour of the multi layer constructions is more complex since the resistance of one layer affects the rate of heat transfer to the adjacent layer. The time lag is not the sum of the time lag of individual layers but it is dependent on the properties of the layers and the sequence in which the layers are arranged. And also emphasized that considerable savings in the material can be achieved by the judicious use of light insulating materials with low heat capacity, and heavy insulating materials with high heat capacity to achieve long time lags without using extreme thickness, which would otherwise be required for the case of a single homogeneous material as in [28]. The effect of thermal capacity in a building component is to delay the attainment of steady state conditions after the heat is absorbed at the external surface. The temperature change at the exposed surface is propagated through the material as a temperature wave, which gradually loses its amplitude as it progresses. For the sinusoidal change of temperature of the exposed surface, the temperature at any point will also be sinusoidal with the same frequency but lags behind the variation at the surface temperature [13]. For a single layer wall the amplitude decrement factor can be calculated by the expression given in the literature as,

$$
\mu=\exp \left(-L \sqrt{\frac{\omega \rho C}{2 k}}\right)
$$

where

$$
\omega=\frac{2 \pi}{(24 .)(3600)}\left(s^{-1}\right)
$$

$L$ is the thickness of the wall, $k$ thermal conductivity $\left(\mathrm{W} / \mathrm{m}^{0} \mathrm{C}\right) ; \rho$ the density $\left(\mathrm{kg} / \mathrm{m}^{3}\right), \mathrm{C}$ the specific heat $(\mathrm{J} / \mathrm{kg} \mathrm{K})$ of the building material. The time lag through multi-layered structure can be calculated with reference to the time constant concept, defined as the time taken for a layer of wall or roof to increase in temperature by a certain perpetration of an instantaneous change in external temperature. Predominantly used materials in building construction industries are brick, stone, concrete, timber and mud. It is essential to understand the thermal behavior of these materials for space conditioning of non air-conditioned building. On the basis of thermal conductivity, density and specific heat of building materials, the thermal characteristics viz. thermal diffusivity, time constant, time lag and thermal transmittance are calculated and the results are given in Table VI. These parameters are predominantly influencing the thermal conditions of the building. The mud wall has shown the largest time lag of $10 \mathrm{hrs}$ and minimum decrement factor as compared to all other options. The Reinforced brick and Brick wall have almost the same value for the overall heat transfer coefficient, different thermal time lag and the decrement factor. It is noted that higher the time lag of materials, the less is the decrement factor correspondingly.
TABLE V: THERMO-PHYSICAL PROPERTIES OF THE BUILDING MATERIALS

\begin{tabular}{|c|c|c|c|c|c|}
\hline \multicolumn{6}{|c|}{ MATERIALS } \\
\hline & DV & $\mathrm{D}$ & $\mathrm{T}$ & $\mathrm{TL}$ & $\mathrm{U}$ \\
\hline Units & $\mathrm{m}^{2} / \mathrm{s}$ & & hrs & $\mathrm{hrs}$ & w/sq. $\mathbf{m}^{\circ} \mathbf{C}$ \\
\hline Concrete(1:2:4) & 8.33 & 0.26 & 10.78 & 4.00 & 3.16 \\
\hline Line concrete & 6.54 & 0.22 & 12.11 & 4.35 & 2.63 \\
\hline Reinforced brick & 4.74 & 0.17 & 15.46 & 5.23 & 2.23 \\
\hline Brick & 6.17 & 0.21 & 12.32 & 4.41 & 2.43 \\
\hline Granite stone & 0.18 & 0.41 & 8.34 & 3.36 & 4.47 \\
\hline Sand stone & 0.12 & 0.33 & 8.41 & 3.38 & 3.54 \\
\hline Mud & 1.95 & 0.06 & 34.99 & 10.34 & 1.79 \\
\hline Wood & 0.17 & 0.40 & 3.40 & 2.07 & 0.70 \\
\hline
\end{tabular}

\begin{tabular}{|c|l|c|c|c|}
\hline $\begin{array}{c}\text { S. } \\
\text { No. }\end{array}$ & Elements & $\begin{array}{c}\text { Density } \\
\left(\mathrm{kg} / \mathrm{m}^{3}\right)\end{array}$ & $\begin{array}{c}\text { Conductivity } \\
\left(\mathrm{W} / \mathrm{m}^{\circ} \mathrm{C}\right)\end{array}$ & $\begin{array}{c}\text { Specific heat } \\
\left(\mathrm{kJ} / \mathrm{kg}{ }^{\circ} \mathrm{C}\right)\end{array}$ \\
\hline 1 & Paver brick & 1600 & 0.69 & 0.84 \\
\hline 2 & Concrete & $1900-2300$ & 1.37 & 0.88 \\
\hline 3 & Glass tiles & 2700 & 0.78 & 0.84 \\
\hline 4 & Gypsum & 1440 & 0.48 & 0.84 \\
\hline 5 & Granite & 2640 & $1.73-3.98$ & 0.82 \\
\hline 6 & Lime stone & 2500 & $1.26-1.33$ & 0.9 \\
\hline 7 & Marble & $2500-2700$ & $2.07-2.94$ & 0.8 \\
\hline 8 & Sandstone & $2160-2300$ & 1.83 & 0.71 \\
\hline 9 & Maple or Oak & 540 & 0.166 & 2.4 \\
\hline 10 & Yellow pine & 640 & 0.147 & 2.8 \\
\hline 11 & Cork & $45-120$ & 0.045 & 1.88 \\
\hline 12 & Ground & 150 & 0.043 & \\
\hline
\end{tabular}

TABLE VI: THERMAL BeHAVIOR OF THE COMMON PAVED/BUILDING

It is found that the diffusivity value (DV) of stone $(0.18$ and $0.12 \mathrm{~m}^{2} / \mathrm{s}$ ) is lesser than the concrete, lime concrete, especially red sand stone. This hard surface can be specified with regard to the decrement factor, and diffusivity to achieve better micro climate. As the paved areas have the backing material as concrete, this can be avoided by specifying the lime mortar. The path ways in the garden, open spaces and other locations can be worked out to have flag stones as far as possible with locally available stone with respect to its thermal behaviour.

\section{CONCLUSION}

A lot of research has been already conducted on the heat gain and heat loss in built environment with various landscape materials. The alarming situation in the energy sector demands an urgent need to create awareness for considering the energy conserving strategies simultaneously along with the early design and construction stages itself. Energy consumption for heating and cooling of buildings can be reduced up to $50-80 \%$ if the building's landscaping and other external features are designed according to the microclimate and the topography of the region. The energy efficient landscape design tools enable decision-making process effectively both at the conceptual and final stage of design of built up areas and it can even be integrated in the 
decision making matrix with respect to landscape parameters for conservation of energy. It is to emphasis the selection of the materials especially in urban areas can reduce the urban heat island effect in general particularly in 'Hot and Humid' and 'Hot and Dry' climatic zones. The landscape design has to be considered to provide thermal comfort in addition to the visual and aesthetical values to the built-up areas.

\section{REFERENCES}

[1] S. Vogel, "Drag and flexibility in sessile organisms," American Zoologist, vol. 24, pp. 37-44, 1984.

[2] S. Vogel, Life in Moving Fluids, Princeton: Princeton University Press, 1981.

[3] C. Yu and W. N. Hien, "Thermal benefits of city parks," Energy and Buildings, vol. 38, pp. 105-120, 2006

[4] M. A. Zwieniecki and N. M. Holbrook, "Diurnal variation in xylem conductivity in white ash (Fraxinus americana L.), red maple (Acer rubrum L.) and red spruce (Picea rubens Sarg.)," Plant Cell \& Environment, vol. 21, pp. 1173-1180, 1998.

[5] S. Yoshida, R. Ooka, A. Mochida, S. Murakami, and Y. Tominaga, "Development of three dimensional plant canopy model for numerical simulation of outdoor thermal environment," presented at the ICUC 6 , Goteborg, Sweden, 2006, pp. 12-16.

[6] J. M. Wondolleck, "Natural Resource Management in the 1990s and Beyond: Problems and Opportunities," prepared for the Pincho Institute's Project on Leadership in Natural Resources, Milford, Pennsylvania, December 1991.

[7] M. Majumdar, Energy-Efficient Buildings in India, TERI Press, 2001.

[8] S. Sandifer and B. Givoni, "Thermal effects of vines on wall temperatures-Comparing laboratory and field collected data," in Proc. the Annual Conference of the American Solar Energy Society, Reno, NV, 2002

[9] N. K. Bansal and J. Cook, Sustainability through Building, New Delhi: Omega Scientific publishers, 2001.

[10] M. Chandra and J. S. Puri, "Cooling and heating of buildings with buried earth-tube heat exchanger: An experimental study," Solar Energy Society of India, vol. 10, no. 1, pp. 1-10, 2000.

[11] N. K. Bansal, "Emerging trends for energy efficiency in Buildings," International Journal of Renewable Energy Engineering, vol. 1, no. 3 , pp. 77-87, 1999.

[12] V. Bharadwaj, S. C. Kaushik, and H. P. Gurg, "Sensible thermal storage in rock beds for space conditioning: A state of the art study," International Journal of Ambient Energy, vol. 20, no. 4, pp. 211-219, 1999.

[13] C. S. Reddy, M. S. R. Murthy, and C. B. S. Dutt, "Vegetation Diversity and Endemism in Eastern Ghats, India," in Proc. the Conservation of Eastern Ghats, Tirupati: EPTRI, Hyderabad, India, 2002, pp. 109-134

[14] S. S. Bharadwaj and N. K. Bansal, "Temperature distribution inside ground for various surface conditions," International Journal of Building and Environment, vol. 16, no. 3, pp. 183-192, 1983.

[15] HUDCO, Buildtech 2001, Building Material and Construction Technology to Housing, pp. 5-19, 2001.

[16] J. Huang, H. Akbari, and H. Taha, "The wind-shielding and shading effects of trees on residential heating and cooling requirements," presented at ASHRAE Winter Meeting, American Society of Heating, Refrigerating and Air-Conditioning Engineers, Atlanta, Georgia, 1990
[17] J. R. Usherwood, A. R. Ennos, and D. J. Ball, "Mechanical and anatomical adaptations in terrestrial and aquatic buttercups to their respective environments," Journal of Experimental Botany, vol. 48, no. 7, pp. 1469-1475, 1997

[18] J. Spangenberg, P. Shinzato, E. Johansson, and D. Duarte, "The impact of urban vegetation on microclimate in hot humid São Paulo," in Proc. PLEA 2007 - Passive and Low Energy Architecture, Singapore, 2007.

[19] S. Vogel, "Drag and reconfiguration of broad leaves in high winds," Journal of Experimental Botany, vol. 40, pp. 941-948, 1989.

[20] D. Phueakphum and K. Fuenkajorn, "A rock fills based solar thermal energy storage system for housing," ScienceAsia, vol. 36, pp. 237-243, 2010.

[21] S. Ramesh, "Energy conservation studies in buildings through components/materials and space conditioning option," Ph.D, thesis, Centre for Energy Studies, IIT Delhi, New Delhi, India, 2004.

[22] N. A. Richards, "Modeling survival and consequent replacement needs in street tree population," Journal of Arboricultur, vol. 5, no. 11, pp. 269-255,1979.

[23] I. G. Simmons, Changing the Face of the Earth: Culture, Environment, History, $2^{\text {nd }}$ edition, Wiley, 1996.

[24] H. Akbari, D. M. Kurn, S. E. Bretz, and J. W. Hanford, "Peak power and cooling energy savings of shade trees," Energy and Buildings, vol. 25, no. 2, pp. 139-148, 1997.

[25] E. Sherry and H. Myers, "Traditional environmental knowledge in practice," Society and Natural Resources, vol. 15, pp. 345-358, 2002.

[26] K. Scott, J. R. Simpson, and E. G. McPherson, "Effects of tree cover on parking lot microclimate and vehicle emissions," Journal. of Arboriculture, vol. 25, no. 3, pp. 129-142, 1999.

[27] N. K. Bansal, G. Hauser, and G. Minke, Passive Building Design: A Handbook of Natural Climatic Control, Amsterdam; New York: Elsevier Science B V, 1994.

[28] S. C. Kaushik, M. S. Sodha, P. K. Bansal, and S. C. Bharadwaj, "Solar thermal modelling of non-airconditioned building: Evaluation of overall heat flux," International Journal of Energy Research, vol. 6, pp. $143-160,1982$

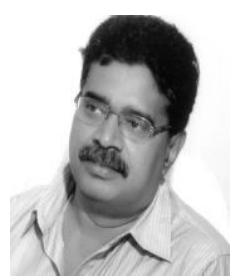

Ramesh Srikonda was born in 1960 in Guntur district, Andhra Pradesh, India. He had acquired bachelors degree in architecture in 1982 in first class with distinction from JN Technological University, Hyderabad, AP, and joined in Anna University, Madras for post graduation in Town and Country Planning and passed out with First class in 1984. He also holds post graduate diploma in ecology and environment from 'Institute of Ecology and Environment', Delhi. He had conducted an extensive research on "Energy Conservation studies in Buildings through Components/Materials and Space conditioning Options." and acquired Doctorate $(\mathrm{PhD})$ from Indian Institute of Technology, Delhi.

He entered into the Central Government Service through UPSC - Central Architectural Services (CAS) in 1985 (Central PWD) and also rendered his professional services in various capacities such as Deputy Architect, Architect, Regional Architect, Senior Architect, Chief Architect and Director of Planning, Slum \& JJ, in Central Government. Presently, he is on a new assignment as the head and a professor of architecture in School of Planning and Architecture, Vijayawada, established by Ministry of Human Resource Development, Government of India. 